\title{
As cidades da juventude em Fortaleza
}

Francisco José Gomes Damasceno ${ }^{1}$

UECE

\section{RESUMO}

A cidade de Fortaleza é apresentada a partir da experiência juvenil, de suas organizações, de seus deslocamentos e de suas formas específicas de apropriação da cidade. Desta observação delineio a idéia de Experiência Musical e de Deslocamentos Geo-Estéticos na cidade. As organizações e experiências juvenis são tomadas como reveladoras de outros possíveis e suas movimentações como manifestação do "novo" urbano contemporâneo.

Palavras-chave: Juventude; cultura; cidade; música; hip hop; punk.

\begin{abstract}
The city of Fortaleza is presented through the juvenile experience of its organizations, its displacements and its specific city appropriation ways. It is from this observation that I take the idea of Musical Experience and the Geo-esthetic Displacements of the city. The organizations and juvenile experiences are considered to be revealing of other possibilities and their movements, as a manifestation of the "new" contemporary urbanity.
\end{abstract}

Keywords: Youth, culture, city, music, hip hop, punk.

Este texto está dividido em cinco partes, em que a juventude e sua atuação na cidade de Fortaleza se esboçam com base na compreensão de sua organização em dois importantes movimentos: o Movimento Hip-Hop e o Movimento Punk. Na mesma medida em que esses jovens se organizam e criam suas organizações, interferem na cidade e nas diversas formas de se organizar e de viver no final do século XX e início do século XXI.

\section{BAILES E CLUBES: A FORTALEZA DAS AFINIDADES ELETIVAS}

Freqüentemente pensei nas cartas geográficas como uma grande metáfora do conhecimento, como tensão entre compreensibilidade e desorientamento. O que faz o cartógrafo? Transfere para uma folha plana de papel o 'mundo real' sob a forma de símbolos e sinais. O que se transcreve é uma 'di- 
ferença': a fonte de toda a informação e, portanto, da comunicação. Ainda assim, enquanto algumas dessas diferenças são imediatamente decodificáveis por qualquer leitor de mapas, outras têm de expressar códigos totalmente novos, de forma tal que até o viajante mais experimentado verá pela primeira vez o lugar representado, mesmo no caso em que tenha estado ali a vida toda. E como a escala 1:1 não adianta, pode servir no máximo a um eu dilatado do narcisismo irrefreável, quanto mais a proporção for reduzida — é micrológi$\mathrm{ca}$ - tanto mais teremos de inventar os códigos a serem transcritos no mapa para deslocar o leitor. Então talvez descobriremos com esses microcódigos que o nosso objeto - a comunicação sincrética — já está incorporando, nas partes terminais de nossos sentidos, enxertos de sensores étnicos, cyber e punk. Mudanças marronizadas. Quilombos patchwork. ${ }^{2}$

No final dos anos 70 a cidade de Fortaleza fervilhava aos sons de inúmeras novidades oriundas da produção da chamada indústria cultural e das culturas de massa. Alguns vindos literalmente 'de fora' e outros considerados 'locais’ e ainda não inseridos no contexto maior de comercialização internacional.

Era o caso, por exemplo, do rock, que aportava com força pela musicalidade de Led Zeppelin, Black Sabbath, Ramones e Sex Pistols, entre outros. Já o predomínio do local se matizava nas inúmeras gravações de forró, bem representados em grupos como Trio Nordestino, Três do Nordeste, Luís Gonzaga, Jackson do Pandeiro e tantos outros.

Estudos sobre o rock em Fortaleza dão conta de uma trajetória iniciada ainda na década de 1950 e um predomínio hegemônico do forró, motivo pelo qual se apontaria, até meados dos anos 90, a dificuldade de 'explosão' dessa manifestação em Fortaleza, bem como do surgimento e consolidação de bandas e espaços destinados a essas manifestações.

Entretanto, o rock praticado em Fortaleza era 'regionalizado', com bandas (ou grupos de bailes) como Os Faraós, Os Belgas, Os Diferentes ou, um pouco depois, $\mathrm{O}$ Peso, que seguiam linhas melódicas mais leves e pouco ligadas às perspectivas mais 'transgressivas':

Na década de 50, o rock era tocado por grupos de baile — o mais conhecido era Iranildo e seu conjunto - que animavam as festas de clubes sociais como o Náutico, Líbano e Maguary ... Na década de 60, com a explosão do rock em todo o mundo, esses grupos tocavam os sucessos do momento, além de músicas brasileiras, mambo, bolero e rumba. O grande destaque era Os Faraós, banda de Luizinho que ainda hoje toca em festas ... Outro destaque era Os Belgas, cujo guitarrista Júlio Sena era o maior sucesso. Tanto um como o outro tinha em seu 
repertório, basicamente sucessos dos Beatles e as versões de Renato e seus Blue Caps. Também vale lembrar d'Os Diferentes, que a exemplo dos demais tocava música dos outros, mas a diferença estava no fato de cantarem músicas próprias e fazerem arranjos diferentes para músicas dos outros ... Nos anos 70, destacouse Luís Carlos Porto, vocalista da banda O Peso, que talvez seja a única banda cearense de rock a ter tido projeção nacional ... No final da década surgiu a banda Posh, fazendo um rock mais para o pop. ${ }^{3}$

Assim, a manifestação nos anos 70 se encontrava na encruzilhada dessas diferentes formas de apreciar e curtir o rock, parecendo ter havido uma apropriação dupla da manifestação:

1) a primeira, do ponto de vista estético-político, com o surgimento de bandas 'mais radicais', com mensagens politizadas e fazendo parte de um 'movimento' que atentava contra os pressupostos anteriores do próprio rock e da cultura de massas - o punk; e

2) a segunda, do ponto de vista dessas manifestações na própria cidade de Fortaleza, e de setores de sua sociedade antes relegados ao 'silêncio'.

Trata-se de uma complexa articulação de manifestações, intenções, padrões estéticos, éticos e práticas de incorporação musical, que dão origem a uma forma inusitada de vivência da cidade e da própria música, que sai dos clubes de elite como o Náutico, Líbano e ou Maguary e passa aos pequenos clubes de periferia, tais como o Apache Clube, o Mênfis Clube do Antônio Bezerra, o Keops Clube, o Detroit, ou ainda o Grêmio recreativo do Conjunto José Walter, entre tantos outros.

É claro que a essa 'transposição geo-estética' (ou 'deslocamento geoestético' $)^{4}$ correspondia uma apropriação de outros setores sociais presentes na cidade de Fortaleza, e, além disso, marcava de forma definitiva a emergência de novos atores sócio-históricos: os jovens pobres.

Situados nas periferias da então pequena cidade de Fortaleza, ${ }^{5}$ eles passam a se manifestar de forma muito mais presente e freqüente, e, além disso, essa manifestação se dá em um campo particular, próprio, singular e inovador: o campo da arte e do lazer.

Assim, os inúmeros bailes que surgem na cidade são mais do que simples diversão e assumem a conotação de manifestação juvenil, que dentro de uma trajetória própria, em pouco tempo, guardando a sua característica histórica de transmutação, assumiria uma outra e mais radical forma de se manifestar, como veremos adiante. 
Os inúmeros bailes geram práticas de sociabilidade, de compreensão estética, ética e musical que são instauradoras de 'territórios existenciais' e possuem suas sutilezas e perspectivas próprias. Vejamos como Flor, à época ainda menina, passa a experimentar o que ocorria:

Eu não sei quando é que a coisa virou movimento punk, porque isso vem de um outro movimento. Eu tinha 12 ou 13 anos, conheci essa menina, a Guacira, ela curtia rock e tinha uns festivais de rock que aconteciam no Apache, no Mênfis Clube do Antônio Bezerra, no Keops Clube, lá no Detroit, várias casas de subúrbio, shows de rock com playback. Era Led Zeppelin, Black Sabbath, Pink Floyd, Kiss, heavy metal. E aí começou uma reunião aqui na Praça do Ferreira. Eu estudava no Anchieta e gazeava aula, ficava no meio dessa galera porque eu gostava de banda e curtia essas coisas. E aí a gente começou a se reunir pra ouvir esses sons, e tinha concursos de dança... ${ }^{6}$

Como se pode perceber na lembrança de Flor, iniciava-se na cidade a produção de pequenas festas nos clubes de subúrbio. Nessas festas, uma das estratégias para envolver os grupos eram competições de rock ao som dos conjuntos ${ }^{7}$ por eles preferidos:

Sempre nos finais de semana uma leva de fãs gravitava pelos clubes suburbanos atrás de diversão. 'Competições' eram travadas entre as diversas turmas. A turma do Baby do Bairro do Monte Castelo, do Conjunto José Walter, do Parque Araxá entre outras, disputava quem agitava mais parecido com seus ídolos (Robert Plant, Ramones), com direitos a guitarras artesanais, feitas de madeira ou papelão e até troféus para as turmas vencedoras. ${ }^{8}$

Além disso, outro aspecto que se deve considerar é a apropriação da cidade de forma itinerante, não fixa, feita de forma 'errante', em deslocamentos pela diversidade de cada bairro ou clube, ou ainda das diversas 'turmas' envolvidas:

Essa coisa do rock não era fixa não, o cara fazia um evento e divulgava, uma semana num bairro, outra semana em outro totalmente diferente ou distante. Acho que era isso que perpetuava a adrenalina. De repente o cara já tem a adrenalina lá em cima, aí faz um evento hoje aqui, no outro final de semana não é mais aqui, é lá...9 
A novidade dessa experiência juvenil que tomava o lazer em suas mãos, articulava os diversos bairros da cidade, se grupalizava a partir de afinidades, identificava grupos distantes e/ou rivais, estabelecia uma rede de relações, de espaços, constituía sua vivência com base em desejos e prazeres dos quais não se dissociava, e, que em breve se tornariam a referência de suas próprias vidas de forma completa. ${ }^{10}$

Estavam constituindo seus espaços:

Existe espaço sempre que tomam em conta vetores de direção, quantidade de velocidade e a variável tempo. O espaço é um cruzamento de móveis. É de certo modo animado pelo conjunto dos movimentos que aí se desdobram. O espaço é o efeito produzido pelas operações que o orientam, o circunstanciam, o temporalizam e o levam a funcionar em unidade polivalente de programas conflituais ou de proximidades contratuais. ${ }^{11}$

A constituição desses 'territórios existenciais' ${ }^{12}$ marca de forma peculiar toda a manifestação juvenil no mundo contemporâneo. Alguns autores têm intitulado essa característica de elaboração de grupos a partir das afinidades e diferenças de 'tribos', ${ }^{13}$ numa dupla alusão à historicidade de processos semelhantes na antropologia e à constituição de redes no universo contemporâneo dito globalizado.

Enquanto para os punks essa articulação inicial se dá no final dos anos 70, para os hip-hopers ocorre processo semelhante no início dos anos 80, com a chegada, primeiro, da dança (break), e depois do canto (rap), e, finalmente, algum tempo depois, do próprio grafite, considerados os três elementos fundamentais do hip-hop.

Os bailes nos quais as diversas sonoridades eram experimentadas em partes específicas para cada estilo musical eram uma prática comum na Fortaleza do final dos anos 70 e dos anos 80 . Assim, os amantes de cada tipo de música tinham uma parte específica das festas para se deleitarem, e a elas recorriam nos mais diversos cantos da cidade.

Não há 'oferta' de bailes específicos, ou seja, de festas com a predominância de uma única manifestação musical, que só aparece, ou se torna forte, predominante, em meados dos anos 90 . Talvez isso indique o pequeno número de freqüentadores dos estilos que depois comporiam o underground em Fortaleza, juntando-os numa estratégia de produção, venda e consumo que atendia naquele momento suas expectativas e possibilidades; ou talvez fosse reflexo de uma outra compreensão de diversão. O certo é que essa junção contribuía 
na formação dos grupos pelo convívio com a diferença, no nascedouro de muitas dessas manifestações como é o caso do rock, do punk, do próprio hiphop e até do forró, que durante algum tempo freqüentam os mesmos pequenos clubes nesses 'bailes mistos'.

Nesse contexto, é interessante lembrar o que afirma Pesavento:

a construção do nós identitário pressupõe a existência do outro. O outro é a concretização da diferença, contraposto como alteridade à identidade que se anuncia. A visualização, identificação e avaliação classificatória do outro acontece sob o signo da estrangeiridade, e é pelo distanciamento - contrastivo, antagônico ou de semelhança - que se pode construir uma noção de pertencimento social. Esta lógica de sentido é, pois, relacional e implica construções que permitem um reconhecimento com sentido. Como diz Ginsburg, todos nós somos em certa medida, estrangeiros com relação a algo ou alguém. ${ }^{14}$

Assim, essa mistura inicial nos pequenos clubes da periferia da cidade criou em Fortaleza uma proximidade entre os diversos grupos que posteriormente se identificam com este ou aquele estilo musical, e, ao mesmo tempo, nesse relacional se identificavam entre si como iguais-diferentes, essencialmente compondo um mesmo campo: o de oposição à sociedade excludente, aspecto que posteriormente será incorporado às suas letras, manifestos, músicas e práticas.

Nesses bailes, nos pequenos clubes dos muitos (e à época distantes) bairros da cidade, integrantes dos diversos grupos se encontravam e aprendiam a se identificar e respeitar:

Inter Dance, no Monte Castelo, era um point dos punks, e em 85, 86, 87 o break estava em ascensão, era de certa forma uma novidade. Lá, o pessoal tinha a festa de rock, punk, e tinha o pessoal que dançava o break, se congregava lá. Aí, alguns deles migraram aqui pro Conjunto Ceará... ${ }^{15}$

Assim, perceba-se: o universo juvenil e o underground eram marcados por um conjunto de práticas que independiam das musicalidades eleitas. Há nesse caso um entrelaçamento entre as perspectivas musicais, as visões de mundo, os interesses mais imediatos e uma aura estética transgressiva que aportava com essas manifestações musicais e que definiu aos poucos o próprio campo dessas manifestações (punk e hip-hop).

Nessas duas manifestações musicais, corpóreas, estéticas, se fundamenta 
um conjunto de vínculos articulados pelo gosto, pela afinidade, pela identificação e identidade comuns e que consubstanciaria nesse período, e nesse processo, os movimentos em suas perspectivas de coletivismo, de crítica e de intervenção social, política e cultural, sendo este último, um 'campo' entendido como essencialmente político e se estabelecendo como o lócus de atuação desses jovens.

No decorrer dos anos 80, tanto o punk como o hip-hop passam por um intenso processo de articulação interna, de articulações políticas, culturais e sociais, no sentido de se fundarem. Eles se criam, por assim dizer, em si mesmos. Estruturam-se enquanto organizações de cunho libertário e de ação contracultural, numa consistente postura de enfrentamento e negação do mercado de bens culturais. Assim, o que era apenas festa, lazer, tornou-se movimentação, e essa movimentação das culturas - como se chamava nos primórdios do movimento - se institui como movimento sócio-político-cultural, como o entendemos com base nos estudos realizados nos últimos anos. ${ }^{16}$

\section{OS MOVIMENTOS}

Hoje existem novos atores, novos movimentos sociais e culturais, tornando visíveis redes direcionadas a valores referenciados no binômio liberdade e sobrevivência, em contraposição às condutas de crise da sociedade contemporâ-

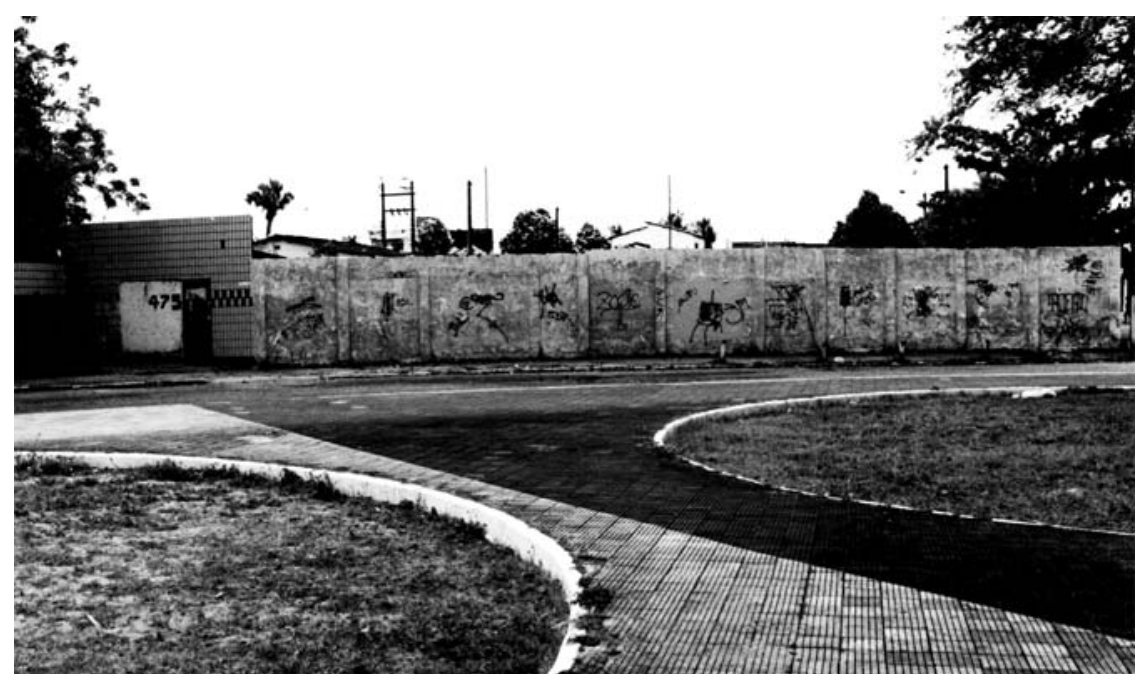

Foto 1 - Internacional (Inter Dance), no bairro Monte Castelo. Fotografia do autor, 2003. 
nea ... As ações coletivas dos anos 90 abrem o leque do próprio conceito de movimento social, permitindo-nos pensar em sua fragmentariedade/descontinuidade como referente de um tempo em que o espaço democrático se relaciona diretamente com a dinâmica entre ação coletiva, cultura política e formação da consciência social das novas gerações. ${ }^{17}$

$\mathrm{Na}$ medida em que essas musicalidades tomavam corpo na cidade, como resultado da experiência direta desses jovens com a música e a própria cidade, foram tomando feições próprias, articulando-se de forma singular como resultado dessa fusão entre os elementos dispostos e construídos. Em outras palavras: foram se tornando 'movimentos'.

Ao que tudo indica, como observa Melucci, nas sociedades contemporâneas, a identidade seria vivenciada como ação e não como situação, sendo construída no complexo de relações sociais estabelecidas no processo de vida e dentro dos meios e lugares sociais ocupados.

Assim, haveria uma alteração na noção de identidade que, baseada nesse pressuposto de constituição permanente, auto-reflexiva, e, sobretudo, operada por cada pessoa, precisaria de novos termos: "A mesma palavra identidade não é mais apropriada para exprimir essa mudança e será necessário falar de identificação para exprimir o caráter processual, auto-reflexivo e construído da definição de nós mesmos"." 18

Dessa forma, o autor quer dar conta da transitoriedade do contemporâneo, da multiplicidade de papéis que cada indivíduo assume cotidianamente. Entretanto, no caso dos jovens desses grupos (punk e hip-hop), uma das suas muitas identidades surgidas no momento de identificação pela música, pela dança, por manifestações afins, e de uma definição de papéis, acaba tornando-se duradoura; o que ocorre é que a grande maioria acaba assumindo de forma definitiva essas identificações (que em princípio são transitórias).

$\mathrm{O}$ fato de esses jovens assumirem uma dessas identificações de forma permanente não significa que o caráter de autoconstrução, de auto-reflexão, seja dispensado, mas parece que o processo se dá de forma intensa, dentro do próprio estilo que assumem. Assim, pode-se falar em identidades da mesma forma ou deslocar o conceito de identidade nesse sentido.

Se, como afirma Maffesoli, "a sensibilidade coletiva, originária da forma estética acaba por constituir uma relação ética”, ${ }^{19}$ então pode-se considerar que esse conjunto de relações instituídas no campo ético/estético, pode se tornar o centro do complexo processo de identificação/identidade, como de fato acontece com muito dos entrevistados. ${ }^{20}$ 
Dessa forma, constituem uma 'linguagem' própria, que articula não só suas falas, mas também os tipos de música, o uso de determinadas roupas e adereços, os símbolos, os locais de freqüência, os usos da cidade, ou as constituições de suas trajetórias da/na cidade, as manifestações do próprio corpo, os cortes de cabelo, as gírias, os aliados, e também, por que não dizer, os próprios adversários. ${ }^{21}$

Essa linguagem articulada dentro do cotidiano é manifesta de forma ostentatória, com a sutileza de seu uso dirigido apenas aos iniciados, de tal forma que mesmo numa multidão, pode-se passar por eles sem percebê-los, num jogo do visível/invisível, em alguns casos.

Em outros casos, o visual é assumido para chocar, impactar, como acontece com os punks, nessa fase. Entretanto, mais recentemente, essa característica é abandonada, em detrimento de uma postura em que esse aspecto se torna opcional. Oliveira nos dá conta de um congresso ocorrido em João Pessoa, em que se discutiu e se deliberou o seguinte: "os que ali estavam concluíram que, o mais importante na sua estética não é a forma 'X' ou 'Y', mas os princípios que a guiam...."22

Assim, pode-se inferir que essa linguagem constituída de símbolos e sinais, pontos geográficos e espaciais, sentimentos e formas diversas de sentir e participar, são incorporadas e desenvolvidas com base em uma noção maior que acaba assumindo proporções cada vez mais significativas tanto em suas vidas como, em resultado disso, na própria vida social e política: o movimento.

É em torno do movimento que tanto punks quanto hip-hopers se insurgem no espaço urbano contra a exploração, a mesmice, a guerra, o capitalismo, a anti-cidadania, a falta de condições de vida dignas e justas, e tantas outras questões que os afligem e incomodam e com o que imaginam estar produzindo um mundo melhor e reinventando sua cidadania.

No início dos anos 90 cria-se na cidade de Fortaleza uma entidade organizativa dos hip-hopers $\left(\mathrm{MH}_{2} \mathrm{O}\right.$ - "Movimento Hip-Hop Organizado do Ceará”) em torno da qual todas as atividades ligadas a essa manifestação se desenrolaram a partir de então. No final da mesma década, muitas outras entidades surgem como 'rachas' da primeira. Hoje, uma outra além dela é forte e ativa na cidade - O "Movimento Cultura de Rua" ou MCR. Esta entidade se coloca como um movimento social organizado, ou pretende se produzir como tal.

Nesse mesmo período a entidade $\mathrm{MH}_{2} \mathrm{O}$ se institui como movimento e cria um estatuto jurídico, tornando-se uma organização não-governamental (ONG), o mesmo ocorrendo com o MCR pouco tempo depois. O trabalho 
das duas é muito semelhante: música, dança e arte são utilizadas no engajamento político, social e profissional dos jovens pertencentes ao movimento. Sutileza que diferencia as entidades das demais, já que o trabalho político vem à frente do musical.

Embora o foco inicial do hip-hop em Fortaleza tenha sido o bairro do Conjunto Ceará, onde até hoje o movimento é muito forte e manifesta-se cotidianamente, com a criação das entidades, com o intenso bombardeio das mídias e a divulgação do estilo, e, principalmente pela atuação do próprio movimento e de suas diversas entidades, toda a cidade, em seus diversos bairros, já é possuída pelos jovens.

De acordo com a nucleação das entidades há uma maior presença de um ou outro movimento nesse ou naquele bairro. Assim, na Quadra de Santa Cecília, onde reside boa parte dos jovens ligados ao MCR, onde se situa sua 'sede' e se desenvolvem suas principais atividades e projetos pilotos, tem-se "uma área do MCR". O Conjunto Ceará "se constitui em uma área do $\mathrm{MH}_{2} \mathrm{O}$ ”, graças aos vínculos históricos com esse bairro. No entanto, suas atuações não se limitam a esses locais e se desenrolam, como já disse, em toda a cidade, muitas vezes concomitantemente, em relações complexas, nem sempre harmoniosas.

Com os punks o processo é semelhante, mas a orientação anarquista imprime um outro viés: a criação de coletivos de convivência alternativa. $\mathrm{O}$ primeiro é criado ainda nos anos 80 (o Núcleo Coletivo de Consciência Libertária - NCCL), e durou até o final dessa mesma década. Depois disso muitos outros vieram, e nos anos 90 o mais presente foi o 'Coletivo Ruptura'. Até recentemente a principal articulação se dava em torno da 'Comuna Libertária', uma entidade sediada no bairro de Parangaba e que encaminha a luta de punks e anarquistas sob essa ótica.

As muitas formas de manifestação de seus desejos e necessidades têm apontado para uma construção alternativa nesses moldes. Além disso, uma articulação local e global ${ }^{23}$ se fortalece com vínculos de solidariedade e trabalho com jovens e entidades de outros estados, como suas movimentações mais freqüentes grafitam, cantam e dançam por aí...

A música iniciada nos 'bailinhos' quebrou as paredes dos clubes de classe média, espalhou-se como um rastro de pólvora, e botou fogo em tudo ao seu redor. Ao lazer puro e simples, juntou-se um outro com prazer misturado à política, à arte, à própria vida, como resposta direta aos desafios cotidianos.

O canto falado e o grito primal nunca foram tão ouvidos e fortes. 


\section{MOVIMENTAÇÕES JUVENIS E TRANSPOSIÇÕES GEO-ESTÉTICAS}

O fato de os punks não possuírem um território fixo na cidade também me conduziu a pensar no território como corpo, ainda mais ao perceber que é nas roupas que o punk estampa seus pensamentos, colocando-se na rua como uma espécie de bandeira do movimento ...

E os critérios dessa seleção não foram os que eu esperava: apego ao lugar, sentimento de pertença, de segurança etc., mas sim critérios de praticidade, de proximidade e de possibilidade. Essas considerações foram tornando a dimensão territorial do punk em Londrina muito mais confusa, pois era diferente do que eu havia tomado conhecimento em teoria ...

Nesse caso, o território não seria propriamente o bar, mas sim a calçada, e os limites do território seriam os corpos. As pessoas que transitam pela calçada desviam do grupo e lançam olhares desconfiados. ${ }^{24}$

O que de fato se pode ler nessa movimentação ${ }^{25}$ é uma apropriação da cidade de forma diferenciada da que ocorria até então. Primeiro, é interessante lembrar que essa nova forma é feita pelo viés da arte, da cultura e do lazer, o que, por si só, já se constitui em uma novidade para essa cidade e sob a influência direta dela, em outras palavras, em resposta aos desafios colocados pela própria vida na cidade. Segundo, pelo inusitado do papel que a música assume nesse processo. ${ }^{26}$ Há um duplo giratório de apropriação da juventude. Por um lado, do ponto de vista social: trata-se de uma juventude de 'periferia' que se manifesta de forma política, social e cultural e insere-se nos mais variados contextos pela sua arte, pela sua música, fazendo disso sua forma de intervenção.

Do ponto de vista estético, dão uma conotação radical ao rock e ao hiphop pela incorporação das condições de vida por eles enfrentadas nesse processo de re-invenção de si próprios, como também pela re-invenção da própria arte por eles praticada. ${ }^{27}$

A apropriação 'geo-estética' da cidade dá-se na medida em que os jovens utilizando-se da arte de viver - como passo a entender sua arte, produzida enquanto ética e estética de vida — produzem outras 'Fortalezas' para viverem, onde os espaços de convivência se tornam referência de bem viver, regados a músicas, festas, prazer e trabalho coletivo de construção dessas utopias juvenis.

A cidade, constituída por essas outras trajetórias, torna-se ao mesmo tempo múltipla, e, além de palco, sujeito, com os jovens em questão, de ou- 
tras histórias. O rock e, pouco tempo depois, o hip-hop, apropriados pelos jovens, servem de elementos de ressignificação da cidade e de suas próprias experiências, e a cidade existente, junto com a cidade criada por eles, servem (ambas) de baliza para sua própria recriação. A reinvenção se dá nesse múltiplo onde tudo e todos se insinuam uns sobre os outros.

O rock que chegou a Fortaleza, em meados dos anos 50, nos salões dos clubes de elite ou das camadas médias urbanas e dentro de certos padrões de socialidade, sendo associado a jovens das famílias mais abastadas, como já o mostramos, aos poucos se altera, é tomado por outros sujeitos (jovens) e os toma, re-inventando a si mesmo, como resultado desse processo de tomar e ser tomado, de inventar e ser inventado, mas também, e, sobretudo, como resultado direto de experiências que se dão com as especificidades do contexto em questão e do meio (cidade) no qual se dão.

Se, no início, o principal clube da cidade e das elites de Fortaleza (Náutico) abrigava o rock, bem como clubes elitizados, embora menos tradicionais (Maguary e Líbano), clubes estes situados à beira-mar (Náutico) ou em regiões centrais e ocupadas por essas elites da cidade, e os grupos de baile 'arrasavam' em ritmos 'frenéticos' com um 'balanço quente, mas respeitoso' (o mais conhecido foi "Iranildo e seu conjunto"), logo em seguida o que se operaria seria muito diferente. Ocorreria uma mudança, dessas regiões das elites para as periferias, sobretudo das camadas pobres da população, e também desses clubes para outros, criados no processo de expansão da cidade rumo às diversas saídas para o interior. ${ }^{28}$

Silva esclarece esse modelo de urbanização, que é duramente criticado pelos jovens punks e hip-hopers em suas letras, em sua arte e intervenção sóciohistórica:

Parte do monstro urbano que conhecemos foi gerado por medidas autoritárias tomadas em gabinetes oficiais, com forte influência de políticos e empresários. A formação de extensas periferias e bolsões de miséria, constituídos quase que unicamente por conjuntos habitacionais distantes e mal servidos, a opção pelo transporte individual em detrimento do transporte coletivo, a facilidade de se implantar novas infra-estruturas que ocasionam a degradação de setores ou bairros tradicionais, expressam essa forma equivocada de produzir a cidade. ${ }^{29}$

Nos anos 60 o rock explode mundo afora e a repercussão dessa onda no Ceará foi inevitável, desta feita misturada a outros ritmos, mas há uma verdadeira proliferação de bandas, como as já apontadas anteriormente — Os 
Faraós; Os Belgas tocando basicamente músicas de outros conjuntos como Beatles e Renato e Seus Blue Caps; e ainda Os Diferentes que tanto tocavam músicas de outros conjuntos com arranjos próprios, como as próprias composições.

Nos anos 70 as bandas continuam a sua atuação em bailes e clubes de elite, como os já citados, mas há certo desgaste na fórmula, tanto pela sua exaustão, por certa repetição, como por outros dois fatores: 1) O rock em todo o mundo sofre mais uma de suas 'revoluções internas', desta vez o punk opera sua obra; e, 2) se inicia um processo, que nos anos 90 se tornaria hegemônico, de construção do forró como ritmo preponderante na cidade, colocado como "autêntico reflexo de nossa regionalidade". Mesmo assim, bandas como a Peso ou a Posh se tornaram bastante conhecidas no cenário local e tiveram suas contribuições nesse contexto.

Assim, nos encontramos com os nossos sujeitos-jovens, jovens-sujeitos, no final dos anos 70, em um cotidiano delicado, refletindo um acentuado crescimento da então pequenina cidade de Fortaleza, graças ao processo de inchaço sofrido pela chegada constante de migrantes oriundos do interior do Estado, que se reflete em espaços compactados, com o surgimento de bairros e loteamentos, e mesmo de favelas (apesar dos altos investimentos nos conjuntos habitacionais planejados e construídos a partir de então) sem os necessários investimentos: lazer, emprego e opções de vida para uma população marcadamente jovem..$^{30}$

A semelhança com os aspectos que dão origem às manifestações de jovens punks (no final dos anos 70) e de jovens hip-hopers (no início dos anos 80) não é coincidência. E a chegada de elementos culturais que traduziam essas realidades em outras partes do mundo parece ter sido amalgamada por esses jovens, incorporada e ter servido de instrumento em seus processos de apropriação do que se constituía para eles: a vida urbana.

Não havia, até então, uma distinção musical, que só viria com o 'amadurecimento' das manifestações. Apenas algum tempo depois é que alguma diferenciação foi percebida e estabelecida, e fomentou, assim, a formação de grupos por afinidades musicais e estéticas: "assim que a gente gostava, que tudo era rock, mas a diferenciação que a gente não tinha conhecimento; que a gente foi conhecendo até por um acaso, rolou de conhecer... aí conheci Sex Pistols, The Clash, The Jam, The Breathers..." ${ }^{31}$

Em outras palavras, o rock e o hip-hop (sofrendo a influência do próprio rock) aportam enquanto musicalidades, agrupam pelo gosto, pela afinidade, pela eleição do ritmo, pela incorporação estética, até mesmo de elementos co- 
mo a dança e outros de dimensão plástica (como o grafite, ou mesmo o da constituição dos visuais), e deste ponto servem de elemento de aglutinação dos jovens identificados com essas manifestações, que passam então a reinventá-las a partir de suas próprias experiências, expectativas e desejos.

Esse ponto de partida - a eletividade ${ }^{32}$ e a comunhão estética e ética tem sustentação em um cotidiano de experiências comuns, de perspectivas de vida semelhantes, e constitui o mais caro no que denominamos de 'experiência musical', algo que está na musicalidade, na música propriamente dita, mas que se constitui diferentemente, apenas a partir do momento em que o que está nas entrelinhas da pauta musical é absorvido, construído por quem ouve e faz música.

\section{OS SONS E A DANÇA - UMA OUTRA EXPERIÊNCIA}

Seu caráter mais importante reside na afirmação da existência de um mundo universalmente obrigatório ... um mundo essencialmente diferente do mundo factual da luta cotidiana pela existência, mas que cada indivíduo pode realizar ... por si mesmo, 'do interior', sem transformação alguma do real ...

Na verdade, mesmo quando a arte protesta contra a miséria social e a solidão, esse protesto é reapropriado esteticamente e solto de maneira gratificante, na experiência imaginária individual, como parte integrante do prazer que a obra lhe proporciona, e não como crítica real e desejo de mudar o mundo. Assim, Marcuse conclui que mesmo 'a idéia rebelde se torna um acessório para a justificação. ${ }^{33}$

É desta forma que se constitui aos poucos o que denominamos de experiência musical, entre encontros furtivos no centro da cidade, nas praças dos diversos bairros periféricos da cidade de Fortaleza, em encontros nas casas para a audição do que 'vem de fora', em bailes e festas para a prática pública da escuta e da dança, no exercício, enfim, da manifestação da forma específica como se resolve constituí-la.

Disto resultam os deslocamentos diferenciados pela cidade em busca de diversão e arte, em busca dos iguais a si, dos diferentes de si, dos espaços para as práticas recém-instauradas de escuta, dança e vivência da música, então novidade na pequena cidade de Fortaleza. Com ela surge toda uma angústia de ser jovem naquele momento, associada a certa rebeldia presente nas musicalidades em questão, veiculadas, sobretudo, em suas letras. 
O que ocorre é que 'música' deixa de ser apenas uma construção melódica e passa a dar sustentação a suas vidas de forma mais ampla. Passa a constituir eticamente, se não todas, pelo menos grande parte de suas ações. Orienta para a vida ou pela vida afora, de tal modo que nos casos dos universos pesquisados nos últimos dez anos (hip-hop e punk rock), todos os jovens envolvidos com essas musicalidades e ou movimentos continuam se pautando por essas perspectivas.

A noção de música se amplia, e tem-se uma outra, a de 'experiência musical', que se entende dentro desse complexo quadro de fusão entre experiências de vida, eletividades afetivas, estéticas e práticas sócio-musicais. E também a dimensão de uma arte enquanto prática, saber-fazer específico, e como tal com uma categoria de agentes ou sujeitos que detêm esse conhecimento. ${ }^{34}$

Essa arte transformada em experiência musical passa a ser construída de forma social por seus sujeitos, que atribuem significados a ela, extrapolando o campo de uma arte fechada em si mesma e se tornando o ponto de articulação entre suas concepções de mundo e suas experiências de vida, dadas no universo do sensível.

Nesse sentido, a dança é outro aspecto da 'experiência musical' que deve ser observado como parte indissociável da musicalidade. O rock trouxe à cena no mundo contemporâneo essa dimensão de forma explícita e irrevogável, e essa apropriação que, em certa medida, rompia com uma postura de contemplação estática, dos modelos anteriores, associados à música de câmara, é, talvez, sua marca mais registrada. ${ }^{35}$

Há uma espécie de dissolução dos sentidos como os conhecemos, de forma que cada um possua uma função específica, empregada quando necessário. É como se todos os sentidos se tornassem um só e fossem empregados na mesma tarefa, ao mesmo tempo. A força da música, das letras, do ambiente, da bebida, da catarse promovida pelos efeitos de tudo isso junto, cria uma forma de sentir diferente, feita com o corpo como um todo homogêneo e indivisível: "Ouvir com o corpo e empregar no ato da escuta não apenas os ouvidos, mas a pele toda, que vibra ao contato com o dado sonoro: é sentir em estado bruto. É misturar o pulsar do som com as batidas do coração, é um quase não pensar". ${ }^{36}$

Da mesma forma que essa dissolução se opera na musicalidade e nas suas danças, opera-se também uma fusão ética/estética, de tal modo que o ideal de beleza das manifestações musicais se transfere para a vida, a vida bela é 'dançada' aos ritmos de suas músicas, e mesmo compreendida diferentemente do que encontram no desigual quadro social no qual estão inseridos. 
Torna-se, então, uma forma política de entendimento e de manifestação aos poucos burilada em uma interação política e social com outros atores sociais, tais como partidos, sindicatos, coletivos, universidades e grupos. A partir disso criam-se os movimentos, caudalosos, com adeptos onde quer que ocorram, em uma 'nação imaginada', ligada pelos sentimentos despertados pela música e construídos com suas próprias especificidades e sutilezas.

As singularidades dos movimentos em Fortaleza estão justamente na criação de suas entidades em torno de uma manifestação inicialmente musical, ou, em outras palavras, na constituição de um movimento sócio-políticocultural em torno do hip-hop e do punk. Portanto, o que antes era música, aos poucos fundamenta-se e se torna movimento. ${ }^{37}$

\section{A INVENÇÃO PELA MÚSICA - DESLOCAMENTOS DA/NA CIDADE}

Nós vemos, toda Cidade é uma espécie de comunidade, e que toda comunidade é constituída em função de um certo bem (porque é em vista de obter aquilo que lhes aparece como um bem realizar sempre seus atos): daí resulta claramente que se todas as comunidades visam um bem determinado, aquela que está mais alta de todas e que engloba todas as outras, visa também, mais que as outras, um bem que é o mais alto de todos. Esta comunidade é aquela que é chamada Cidade, é a comunidade política. ${ }^{38}$

Assim, a experiência musical desses jovens é um aspecto que deve ser levado em consideração no deslocamento dos clubes de elite para os clubes de periferia. Trata-se de uma juventude pobre e de periferia se manifestando e tendo a atenção de setores sociais diversos.

Saímos do Maguary, do Líbano e do Náutico, de grupos de baile como "Iranildo e seu conjunto", e, de uma musicalidade comportada e aceita, para clubes de periferia como o Apache, o Mênfis Clube do Antônio Bezerra, o Keops Clube, o Detroit, entre tantos outros, produzidos enquanto espaços por jovens pobres, muitas vezes radicais, e de periferia, com bandas como Estado Indigente, Zueira, Desnutrição, e rappers como Titio e Cachorrão, W Man, Poeta Urbano e ZMC, entre tantos outros.

Esse deslocamento que é ao mesmo tempo geográfico, posto que se faz dos espaços das elites para os espaços populares, tem ao mesmo tempo um caráter de classe e etário, já que é operado por jovens trabalhadores, ou mesmo jovens sem profissão, desempregados e pobres, ou ainda estudantes, por- 
tanto, em formação para o mundo do trabalho, habitantes dos bairros mais pobres de minha cidade.

Também tem um caráter estético, já que dentro das duas manifestações o que ocorre de forma invariável é uma sucessão de transgressões estéticas de cada uma dessas musicalidades, além de ser uma transgressão também para o tipo de música (mesmo de rock e de hip-hop) feito em Fortaleza no período. Fortaleza jamais havia visto algo tão 'radical'. Além disso, essa dimensão transgressiva de alguma forma constituiu os seus repertórios de compreensão e de articulação estética e posteriormente também política.

Amalgamando todos esses aspectos, consubstanciados nesse deslocamento, estão suas experiências de vida, suas experiências musicais, que dão a esse movimento um caráter de duplo deslocamento, por um lado estético e por outro geográfico, ou mesmo geopolítico, daí por que falamos em deslocamentos 'geo-estéticos' em Fortaleza.

Utilizo a noção de 'deslocamento geo-estético' ${ }^{39}$ como uma fusão do espaço geográfico e da manifestação estética e que dá sentido a esses espaços, configurando assim, com base na idéia de que o espaço é o lugar praticado, ${ }^{40}$ uma outra dimensão: a dimensão da arte de viver, de viver com as referências de beleza por eles instituídas, e, assim, elegendo as trajetórias a serem estabelecidas dentro do universo urbano, que redimensiona o espaço a partir da arte (música, dança) e instaura a cidade na qual vivem, dentro das muitas cidades existentes na cidade de Fortaleza.

\section{EXPERIÊNCIAS MUSICAIS, DESLOCAMENTOS} GEO-ESTÉTICOS: AS CIDADES E OS JOVENS

As leituras construídas pelos jovens em suas letras e manifestos guardam características peculiares. Vejamos especificamente e de forma rápida o caso de algumas noções dos jovens punks e hip-hopers. Em primeiro lugar, como a sociedade que emerge de suas letras nos é re-apresentada; em seguida, a noção que têm de si próprios.

Emerge de suas letras uma cidade identificada com a divisão social, ou uma 'sociedade' constituída a partir de suas experiências na/da cidade. Assim se caracteriza uma cidade/sociedade marcadamente repressora, desigual, dividida, exploradora e injusta. É entendida como a máxima manifestação organizacional humana e, portanto, o que se representa é uma humanidade dividida e à beira de um tipo qualquer de colapso. 
Divididos em classes, os raps e punk rocks são construídos com a intenção de serem a fala das minorias sem voz, dos injustiçados, marginais, prostitutas, mendigos, meninos de rua, trabalhadores, e, sobretudo, das periferias, do povo pobre, operários e desvalidos. ${ }^{41}$

pois nós somos a voz da periferia / o grito do gueto / o argumento da pobreza / pra lutar-brigar... ${ }^{42}$

Ossos quebrados / Mente vazia / Olhos arrancados / Intestino apodrecido / Retrato operário / Pobre indigente / Largado jogado / Vítimas inocentes / Largado jogado / Estado esquecido / De putrefação / De imperialismo / Diferença social / Grito de dor / Invasão militar / Só carnificina / Não há sobrevivência / Minha vida esquecida / Não há sobrevivência / Sua vida apodrecida. ${ }^{43}$

A sociedade para eles é a 'encarnação' dessas diferenças, e, portanto, a sua manutenção é necessária para quem delas se beneficia. Identificados como os inimigos, os ricos são o principal alvo:

a sociedade fecha as portas na cara de quem nada tem / pois as portas são fechadas / grades seladas / pois é isso que convém antes de você / cometer o delito / delito ou ato de sobreviver... ${ }^{44}$

Em outro rap se mostra concretamente como essa sociedade de ricos se fecha:

De que vale o Beach Park se eu não posso entrar? / de que me serve o Iguatemi se eu não tenho 'grana' pra gastar? / carro importado pra quê se eu não posso comprar? ${ }^{45}$

A inclinação desses jovens à esquerda (não única) a partir da criação de seus movimentos e de articulações com partidos políticos, sindicatos, ONGs, coletivos e outras instituições revela que

a cidadania não é uma construção meramente voltada e construída pelo político, embora possa vir a ser desta forma enunciada. A questão social aparece como um problema posto pelo desenvolvimento das cidades, e uma das formas do seu enfrentamento é o deflagrar da construção da cidadania. ${ }^{46}$

A aparição no universo citadino é uma intervenção de conquista dos direitos elementares negados, e as suas letras, os seus manifestos podem ser en- 
tendidos como a fala de sujeitos sociais em ebulição na dividida cidade de ricos e pobres, na Fortaleza de muitos caminhos possíveis e instituição de seus desejos de cidades outras.

Eles se apresentam aos poucos, em indícios sutis do lugar social de suas falas. Isso pode ser observado em um dos primeiros raps do movimento a fazer sucesso, em toda a cidade, o "Rap da Dora" da dupla Titio e Cachorrão. Nele o trabalho é identificado ao sofrimento - leia-se o trabalho que não recompensa - criando a necessidade de espaços onde o sofrimento deve ser substituído pela alegria e pela vida.

Expressa de forma ambígua a Dora: "boto a mão na cabeça é tão bom como me sinto / pois nesses dias não tem que trabalhar fico em casa a se ajeitar / pois nesses dias quer também se divertir...” - observe-se que o sujeito 'eu' elíptico e depois indefinido pelo uso da partícula 'se', provocando uma automática identificação/confusão autores/Dora - como se por sua boca eles falassem, mostrando como se sentem estes jovens que, imersos no mundo do trabalho, na tensão nele estabelecida, encontram nos bailes, nos momentos de diversão e lazer, uma das poucas alegrias que têm. ${ }^{47}$

Também nos punk rocks a condição operária é sentida em manifestos, documentos, músicas:

A vida de operário é um tormento / A vida de operário é um sacrifício / Pra viver $(2 \mathrm{x})$ / Sem razão (2x) / Escravo moderno nos campos / Escravo moderno nas fábricas / Pra viver (2x) / Sem razão (2x) / Viver pelas leis dos patrões / Condenados à pena de morte / Pra viver $(2 \mathrm{x}) /$ Sem razão $(2 \mathrm{x})^{48}$

Eis que se revelam suas faces: jovens trabalhadores da cidade. Pequenos operários, desempregados, mão-de-obra pouco qualificada e barata, que na cidade através de sua arte se produz enquanto grupo e aponta os sérios problemas que os cercam e demandam solução imediata.

A cidade apartada aparece em vários momentos, como neste trecho:

quem vê Fortaleza como no resto do Brasil / vê estupro, assassinato, corrupção desenfreada / temos brigas de gangues / assaltos a mão armada, traficantes de maconha e polícia bem safada / os garotos roubando lá na praça da estação / e no passeio público tem até prostituição / sem esquecer dos mendigos lá do centro da cidade / e dos apatoladores que existem aos milhares / temos mortes no trânsito e muitos viciados / motoristas imprudentes e hospitais superlotados / temos roubo de carro e cheques sem fundos / pode crer na capital nós temos de 
tudo / o nosso Ceará com todos seus problemas / é o rap do Conscientes do Sistema (3x) / aqui também tem desemprego aumentando a violência / e escolas do governo numa tremenda decadência / temos rádio e TV / revista e jornal / essa merda que ilude e nos fazem passar mal / distorcendo as notícias isso eles fazem muito bem / transformando em marginais muitas pessoas de bem / essa é a dura realidade quem tem grana mata e rouba e ainda fica em liberdade / ao contrário do pobre que não tem nada e é fodido / só por causa da aparência leva nome de bandido / temos o Iguatemi e o Shopping Aldeota / a rota dos burgueses que nos vêem como idiotas / temos fome e miséria e até racionamento / gente inocente passando o maior tormento / "eu sou a nata do lixo eu sou o luxo da aldeia eu sou do Ceará” (sampler) / o nosso Ceará com todos seus problemas / é o rap do Conscientes do Sistema $(3 \mathrm{x})^{49}$

Outra letra bastante significativa de suas idéias sobre si e sobre a cidade é "Nativo Urbano", da banda Estado Indigente:

Mesmo que eu morasse / No mundo sozinho / Mesmo que eu morasse / Em mundo perfeito / Tocava hardcore pra vida / Com prazer (2x) / E nada me impediria / Consciência, capacidade e prazer / Virtudes de poucas viventes / No habitar sonolento da vida / Almeja sonho impotente / Desmotiva pela inconsciência / De outros / Paralelo, direto, nostálgico.

A consciência de si e dos outros, a possibilidade de intervenção direta, operada pelo sujeito consciente, apesar da identificação da vida aos bailes, revela certa tristeza, oriunda decerto de suas origens, ou dos meios nos quais se manifestam: as ruas. ${ }^{50}$

O espaço da rua, longe de ser o espaço de 'deambulação' como é significado para os rockers, ${ }^{51}$ constitui-se em espaço de vivências, de violência, de amores, de lutas, de revolta, torna-se o palco de suas vidas, o local onde vivendo, buscam inspiração para suas letras, ou ainda onde vivem as histórias que suas letras contam.

Locais perigosos e instáveis, onde se corre o risco de viver. Seus habitantes, longe da calma das casas, da segurança das famílias, da limpeza e higiene dos lares normais, são múltiplos e dividem a agitação, o vai-e-vem de transeuntes, a insegurança da luta pela sobrevivência, a sujeira causada pelas aglomerações etc.

É o espaço da violência, da morte, da dor, da fome, da miséria, dos desvalidos, dos marginalizados, dos menores abandonados, delinqüentes, prosti- 
tutas, pobres e desocupados. Tipos como o 'vagabundo', que, como nos mostram B.Girl e Rainha, "vive pelas ruas do centro da cidade":

aonde a cada esquina um assalto acontece ... marginais andam a solta, trombadinhas cheiram cola / se não preferem o roubo muitos deles pedem esmola / são jogadores nas ruas pra ganhar algum dinheiro / mas as ruas lhes ensinam o verdadeiro desacerto... ${ }^{52}$

se os meus filhos estão nas ruas / suas vidas aventuram lances, mortes, extermínio ... Rap e Hip-Hop nas calçadas da cidade / o Break violento e forte... (grifo meu $)^{53}$

As ruas tomam conta desses seres / menores carentes ninguém quer saber deles ... aqui trombadinhas aumentam a cada dia / menores nas ruas, crianças perdidas / filhos das ruas, quem vai tirá-los da rua? / quem os fará viver? / ... e você...? / mas vocês são todos iguais / em suas casas tão em paz / longe das ruas, longe da sujeira, longe da vida imunda / eu aqui e você na sua / e os menores carentes estão todos nas ruas / filhos da rua / filhos da rua / sem-tetos dormindo nas praças / ... matar ou morrer faz parte da vida / da vida na verdade não são inocentes são vítimas conseqüentes / crianças delinqüentes / ... prostituir o próprio corpo em troca de quase nada ... / flanelas na mão pedindo um trocado / sem esperanças, sem família, nas ruas jogados / não existe para eles sonho algum / vivem o presente sem futuro nenhum... ${ }^{54}$

No percurso pelas trilhas abertas na cidade, na instauração das muitas cidades, se estabelecem marcações, se estabelecem territórios no andamento da vida. Eles instituem os seus marcos, ou pequenos portos no mar da cidade.

Depois de algum tempo, as turmas punks passaram a se encontrar na região do centro da cidade, na Praça do Ferreira, depois na Praça José de Alencar; os rappers em locais específicos nos bairros, como o Pólo de Lazer do Conjunto Ceará, que se constituíram em points, onde eram 'trocadas as idéias' e traçadas as trajetórias de cada final de semana:

Eu estudava ainda, vinha à Praça José de Alencar, que de certa forma sempre foi um point, aqui em frente ao teatro todas as sextas tinha um grupo tocando $\mathrm{MPB}$, música daqui mesmo. Aí, os mesmos roqueiros que pintavam lá no Grêmio do José Walter se reuniam todas as sextas aqui nessa praça ou então na an- 
tiga Praça do Ferreira, e aí a gente foi se entrosando. Quando não queria ir pra casa, ia pro Monte Castelo, a gente virava a noite, ficava ouvindo som... ${ }^{55}$

Nos points se decidia a programação do final de semana, marcavam-se os encontros, escolhiam-se os melhores programas, além, é claro, da tradicional 'troca de idéias':

Nessa época eu não tinha muito tempo, porque eu trabalhava durante o dia $\mathrm{e}$ estudava à noite, mas foi uma das épocas que eu vacilei mais com o estudo. Eu deixava de ir pro colégio pra pintar nos points às quartas e sextas, ali na Praça do Ferreira. E tinha um dos primeiros clubes com sons de bandas, só Ramortes que tocava na época, o Davis Clube, lá na pista da Barra. Que lá o cara aloprava todas as quartas, sextas, sábados e domingos, quando a banda não tocava era som de fita....

O point nunca era o fim de uma trajetória e ou de uma jornada, mas sempre o seu ponto inicial, o local de encontro, o ponto de referência em torno do qual todos aqueles que queriam podiam se encontrar. $O$ fim da jornada, quando não havia um baile em jogo, era a experiência comum de ouvir música, de trocar idéias e depois fazer as próprias músicas, aprender como tecer sua arte:

a gente se reunia ali, e ia pra casa dum, pra casa do outro, do João Wilsom, aí ficava lá, ouvindo o som, trocando idéia, fazendo música... Era isso quase todo dia. Nos finais de semana, sempre tinha os locais pra gente ir, uma banda que ia tocar... Descia pro Davis Clube, que quase todo dia tinha som lá... ${ }^{57}$

O point, no entanto, era mais do que um local. Em inúmeros momentos andei, divaguei, pontuei, trilhei as cidades dos desejos dos jovens. Nosso deslocamento em bando causava medo e reações diversas nas pessoas

pois a caminhada vai adquirindo uma autonomia de point, nesse durante conversamos, um espera o outro ou se adianta para falar com alguém que está na frente. Poderíamos talvez não chegar. Big me diz rindo: 'acho que a gente está andando por andar..$^{58}$

Ruas e praças, clubes, centros comunitários, casas e universidades, sedes de sindicatos, movimentação na cidade e pela cidade que suas experiências diretas instituem, criam como espaço de vida. As apropriações feitas revelam outras possibilidades, outras formas de perceber o mundo e também de criá-lo. 
Talvez caminhem esses jovens por caminhos que não vemos, mesmo quando os seus deslocamentos se fazem nas ruas que vemos, nas praças nas quais sentamos, conversamos... talvez cantem esses jovens realidades que não conseguimos sequer imaginar, compreender.... talvez essas outras realidades, cidades, estejam no limiar de suas experiências e reflitam essa ambigüidade, pois:

Enquanto o adulto vive ainda sob o impacto de um modelo de sociedade que se decompõe, o jovem já vive em um mundo radicalmente novo, cujas categorias de inteligibilidade ele ajuda a construir. Interrogar essas categorias permite não somente uma melhor compreensão do universo de referências de um grupo etário particular, mas também da nova sociedade transformada pela mutação. ${ }^{59}$



Foto 2 - Davis Clube (extinto). Fotografia do autor, 2003.

\section{NOTAS}

' Pesquisador ligado ao Grupo de Práticas Urbanas do Mestrado Acadêmico em História - Mahis, e do Labvida — Laboratório de Direitos Humanos, Cidadania e Ética do Mestrado em Políticas Públicas também da UECE.

${ }^{2}$ CANEVACCI, Massimo. Conclusão em forma-de-mapa. In.: Sincretismos: uma exploração das hibridações culturais. São Paulo: Studio Nobel; Instituto Cultural Ítalo Brasileiro-Instituto Italiano de Cultura, 1996. p.91.

${ }^{3}$ VIEIRA, Roberto César. Pedras que não rolam criam limo: rock cearense - consumo e mercado. Monografia apresentada ao curso de Comunicação Social, Universidade Federal do Ceará. Fortaleza, 1994. p.57-8. 
${ }^{4}$ Mais à frente comentarei a noção de deslocamento geo-estético.

${ }^{5}$ A matéria do Diário do Nordeste, 16 jan. 1982, p.7, dava conta das dimensões da cidade: "Com um milhão e trezentas mil pessoas, Fortaleza só tem sete creches". Muitas outras notícias dão a dimensão das carências da cidade, como por exemplo: "Comunidades carentes reclamam das péssimas condições de vida”, Tribuna do Ceará, 21 jan. 1980, p.7; ou ainda: "Passagem cara faz o povo andar a pé", Diário do Nordeste, 24. dez. 1981, capa, onde se anunciava o presente de Natal dos fortalezenses, um aumento das passagens de ônibus. Algum tempo depois, em reação explícita a essa situação o movimento punk decreta uma campanha pela gratuidade do transporte coletivo em Fortaleza, com o 'desça por trás'. Cf. "Fora aumentos, chega de exploração, coletivo grátis já!”, nota/panfleto, Fortaleza, s.d. Diziam eles em determinado momento: "Chega! Chega!... Tá na hora de dizer um basta a tudo isso. Só vão aprender quando a população se revoltar. Por isto estamos propondo que os trabalhadores reajam diante dessa situação. Vamos subir por trás, pular a catraca, conversar entre nós e vamos lutar pelo transporte coletivo gratuito. Já estamos pagando caro demais em impostos e ainda sermos obrigados a enriquecer mais e mais os bolsos desses safados, enquanto o povo morre de fome? Não! Chega! NCCL — Núcleo Coletivo de Consciência Libertária e MAP — Movimento Anarco-Punk".

${ }^{6}$ Entrevista realizada por este pesquisador, com a ex-integrante do movimento punk, à época chamada Flor Punk, na Praça dos Leões, centro da cidade de Fortaleza, em 6 mar. 2003. p.2-3.

${ }^{7}$ Carmo nos informa que, nesse período, o termo 'bandas' não era empregado. Cf. CARMO, Paulo Sérgio do. Culturas da rebeldia: a juventude em questão. São Paulo: Ed. Senac, 2001. $279 \mathrm{p}$.

${ }^{8}$ XIMENES, Amaudson. A música underground em Fortaleza: resistência ou crise de identidade? Monografia apresentada ao curso de Ciências Sociais, Universidade Estadual do Ceará. Fortaleza, 1998. p.34. É interessante frisar que Ximenes é guitarrista da banda Obskure, e fundador da Associação Cearense do Rock (ACR). Roqueiro 'de primeira hora', vivenciou esse período e alguns dos acontecimentos que narra, tendo em dado momento desenvolvido alguns trabalhos com os punks em Fortaleza. Foi entrevistado no sentido de delinear a ação dos grupos punks, e de identificar as relações estabelecidas nesse momento de surgimento do punk na cidade.

${ }^{9}$ Entrevista realizada por este pesquisador com 'Magoo', em 28 jan. 2003, em sua residência na cidade de Caucaia, região metropolitana de Fortaleza. p.1. Magoo foi um dos principais expoentes do punk durante os anos 80 e 90, distanciou-se do movimento organizado, mas continua com a banda Estado Indigente, que formou ainda no final dos anos 80 .

${ }^{10}$ A priorização total do estilo ocorre com a maioria dos entrevistados da pesquisa realizada com punks e hip-hopers na cidade de Fortaleza.

${ }^{11}$ CERTEAU, Michel de. A invenção do cotidiano. Artes de Fazer. Petrópolis (RJ): Vozes, 1999. p.202.

${ }^{12}$ Cf. JANOTTI JR., Jéder S. Heavy metal: o universo tribal e o espaço dos sonhos. Dissertação (Mestrado) - Depto. de Comunicação Social, programa de mestrado em Multi- 
meios, Unicamp. Campinas, 1994. Segundo ele através "do vestuário, dos shows e dos locais de encontro do grupo, os jovens procuram construir 'territórios existenciais' que possibilitem exercitar sua subjetividade situada além dos espaços normatizados (tais como família, escola e trabalho)".

${ }^{13}$ MAFFESOLI, Michel. O tempo das tribos: o declínio do individualismo nas sociedades de massa. Rio de Janeiro: Forense-Universitária, 1987.

${ }^{14}$ PESAVENTO, Sandra Jatahy. Uma outra cidade: o mundo dos excluídos no final do século XIX. São Paulo: Cia. Ed. Nacional, 2001. p.11-2.

${ }^{15}$ Entrevista realizada por este pesquisador com o rapper Sátiro Silvestre, no dia 10 ago. 2003, no bairro do Conjunto Ceará, em Fortaleza, p.1. Atual integrante da coordenação do $\mathrm{MH}_{2} \mathrm{O}$ e um dos primeiros dançarinos de break da cidade, foi um dos fundadores da Striking gangue de break nos anos 80.

${ }^{16}$ Cf. DAMASCENO, Francisco José Gomes. O movimento hip-hop organizado do Ceará 1 $\mathrm{MH}_{2} \mathrm{O}$-Ce (1990-1995) Dissertação (Mestrado) — Pontifícia Universidade Católica de São Paulo. São Paulo, 1997.333p.; e DAMASCENO, Francisco José Gomes. Sutil diferença: o movimento punk e o movimento hip-hop em Fortaleza — grupos mistos no universo citadino contemporâneo. Tese (Doutorado) — PUC-SP, São Paulo, 2004. 511p.

${ }^{17}$ SOUZA, Janice Tirelli Ponte de. Reinvenções da utopia: A militância política de jovens nos anos 90. São Paulo: Hacker, 1999. p.93-4.

${ }^{18}$ Melucci, citado em CARRANO, P. C. R. Juventude — as identidades são múltiplas. Revista Movimento, São Paulo: DP\&A, n.1, maio 2000. O mesmo Melucci (1997) propõe em outro artigo que se deveria falar em redes conflituosas, em vez de em movimentos, dado o caráter de produção de formas culturais. Apesar de interessante, no caso dos movimentos aqui estudados não se aplica, posto que os significados construídos por esses jovens passam pela noção de movimento.

${ }^{19}$ MAFFESOLI, Michel. O tempo das tribos..., cit., p.27.

${ }^{20}$ É interessante observar que todos os entrevistados desta pesquisa têm o estilo no centro de suas atividades, sejam elas profissionais, sociais, políticas etc. Há a priorização total do estilo, que assume a dimensão de ordenador das relações. Neste caso, o termo 'identidade' se aplica perfeitamente.

${ }^{21}$ De um modo geral, cada entrevistado tem sempre uma história de como ocorreu consigo, ou mesmo com outros do grupo.

${ }^{22}$ OLIVEIRA, Vantiê Clínio de Carvalho. O movimento anarco-punk (A identidade e a autonomia nas produções e nas vivências de uma tribo urbana juvenil). Dissertação (Mestrado) - Programa de Pós-Graduação em Ciências Sociais, UFRN. Natal, 2003. p.47. Apesar de o estudo versar sobre a cidade de Natal, a referência é feita com relação a um congresso dos anarco-punks ocorrido na cidade de João Pessoa.

${ }_{23}$ "No interior desses remoinhos flutuantes e plurais de panoramas glocal, emerge com força a produção, a difusão e o consumo de sincretismos culturais. Essa palavra nova, fruto de recíprocas contaminações entre global e local, foi forjada justamente na tentativa de 
captar a complexidade dos processos atuais. Nela foi incorporado o sentido irrequieto do sincretismo. O sincretismo é glocal' (grifos meus). CANEVACCI, op. cit., p.25.

${ }^{24}$ TURRA NETO, Nécio. Enterrado vivo: identidade punk e território em Londrina. São Paulo: Ed. Unesp, 2004. p.100, 104, 117.

${ }^{25}$ 'Movimentação' aqui se entende por 'tornar-se movimento' e, ao mesmo tempo, como ação dinâmica dos jovens em fazer, criar, inventar-se enquanto processo complexo de relações sociais, políticas, culturais, artísticas etc.

${ }^{26}$ É interessante frisar que música, aqui, se configura basicamente pelo rock e demais manifestações underground, que tendo o rock como referência se posicionam como elemento de transgressão de determinados setores, sobretudo da juventude contemporânea, assumindo o caráter de instrumento de crítica social e política.

${ }^{27}$ Refiro-me aqui a arte como prática, como defendido por SHUSTERMAN, Richard. Vivendo a arte: o pensamento pragmatista e a estética popular. São Paulo: Ed. 34, 1998.

${ }_{28}$ "Nossa cidade teve seu processo de metropolização e expansão da malha urbana direcionado pelas suas principais vias rádio-concêntricas, herança de seus antigos caminhos como o do Soure, antigo nome de Caucaia, que provocou o adensamento urbano na porção oeste da cidade". SILVA, José Borzacchiello da. Nas trilhas da cidade. Fortaleza: Museu do Ceará; Secretaria de Cultura e Desporto do Ceará, 2001. (Coleção Outras Histórias). p.70.

${ }^{29}$ Ibidem, p.103.

${ }^{30}$ Cf. SILVA, José Borzacchiello da. Movimentos sociais populares em Fortaleza: uma abordagem geográfica. Tese (Doutorado) - Departamento de Geografia, Universidade de São Paulo. São Paulo, 1986. Os inúmeros migrantes expulsos do interior e sem a certeza de qualidade de vida em terras distantes fazem de Fortaleza um pólo atrativo, não só pela sua proximidade. Este dado evidencia a enorme influência do 'sertão' ou do 'campo' na cidade de Fortaleza e em suas manifestações culturais.

${ }^{31}$ Magoo, cit., p.1.

${ }^{32}$ São muitas as narrativas que citam esse aspecto, de tal modo que se pode avaliar o papel da eletividade como fundamental: Sátiro Silvestre, um rapper, ex-breaker, e desde o princípio ligado ao hip-hop, em tom de brincadeira, alude ao tempo que já tem de 'movimento': "Era uma vez... (risos) cara meu contato com o hip-hop foi... desde os 12 anos, faz tempo... mas foi aqui na comunidade mesmo, nas festas que tinha, que eu via a galera dançando break, a rapaziada que antecedeu a gente, que era o Lula, não tinha nada organizado, mas o pessoal que dançava lá no Inter ... Inter dance, no Monte Castelo, era um point onde os punks, e no tempo... 85, 86, 87 o break tava em ascensão, era de certa forma uma novidade, aí lá o pessoal tinha a festa de rock, punk, e tinha o pessoal que dançava o break se congregava lá, aí eles migraram alguns aqui pro Conjunto Ceará, aí foi quando eu vi o Lula fazendo o Moinho de Vento eu endoidei, 'meu irmão, como é que esse cara faz isso?'. A partir daí, fui chegando na roda e me engajei, a a partir daí foi o $1^{\circ}$ contato mesmo com o hip-hop... (Entrevista realizada com Sátiro em 10 ago. 2003, no bairro do Conjunto Ceará em Fortaleza). 
${ }^{33}$ SHUSTERMAN, Richard. Vivendo a arte..., cit., p.68-9.

${ }^{34}$ A idéia da arte enquanto prática sócio-histórica, desenvolvida por Shusterman, foi uma das que mais me auxiliaram na compreensão dos fenômenos da arte e da cultura juvenil.

${ }^{35}$ Alguns autores sugerem essa prática como uma metáfora da vida cotidiana urbana contemporânea. Aqui nos interessa apenas anotar a dança como parte indissociável da experiência musical.

${ }^{36}$ MORAES, Jota de. O que é música. São Paulo: Nova Cultural; Brasiliense, 1986.

${ }^{37}$ Cf. DAMASCENO, cit., 2004. A constituição dos movimentos punk e hip-hop como movimentos juvenis sociais contemporâneos é desenvolvida nesse trabalho.

${ }^{38}$ Aristóteles, cit. em PESAVENTO, Sandra Jatahy. A vitória de Antígona sob o signo de Babel, a cidade brasileira dessacralizada. In: PESAVENTO, Sandra Jatahy (Org.) Escrita, linguagem, objetos: leituras de história cultural. Bauru (SP): Edusc, 2004. p.168.

${ }^{39}$ Faço assim uma apropriação livre de conceitos como o de 'geopolítica', por exemplo, e, dilato seu sentido, reinvento o seu uso e o avalio sob a ótica de que a manifestação juvenil contemporânea é essencialmente cultural e nisso reside a articulação entre cultura e política para esses sujeitos: uma intervenção cultural, social e artística na cidade, que é marcadamente política pela crítica e pelas práticas que estabelecem.

${ }^{40} \mathrm{Cf}$. CERTEAU, Michel de. A invenção do cotidiano..., cit.

${ }^{41}$ Essa é uma pretensão assumida por eles próprios, e colocada e reexposta constantemente. Sente-se isso nas entrevistas realizadas com eles no Ceará, e essa também é uma característica mais geral do rap. Mano Brown, líder dos Racionais MCs declara (Folha de S. Paulo, Ilustrada, 7 maio 1994, "A vez do Rap".): "Não sou porta-voz do movimento hip-hop, mas da periferia talvez!". Cf. ainda as matérias “Tiroteio na Periferia”, em O Globo, 30 jun.1994; "Rap é a língua oficial da periferia” Estado de S. Paulo, 27 nov. 1992, e ainda “Rap'eriferia” no jornal O Povo, caderno Tribos, 15 maio 1994.

${ }_{42}$ "Mais do que nunca a Fortaleza é DEF" - O grupo Ataque Frontal era composto pelos rappers ZMC e Ligado. Ambos participam do movimento, aproximadamente desde 1993. ZMC é um dos membros mais engajados com setores diversos das 'esquerdas' como o Movimento Estudantil e Popular. Depois de trabalhar como lavador de carros à noite no estacionamento de casas noturnas da cidade, tem trabalhado como prestador de serviços na Câmara de Vereadores de Fortaleza. Ligado, além de seu vizinho na favela da Quadra, no coração da Aldeota, sem profissão definida, trabalha como vendedor de pequenas lojas de grifes locais e como servente de pedreiro, quando não faz pequenos biscates.

43 “E x I" - Estado Indigente.

${ }_{44}$ "Sem Título" - Realidade em Cadeia. A pergunta insistentemente repetida nesse rap é "Quem são os mandantes, quem são?" e "Olhe pra cima e veja então, quem é que mata sem arma na mão / me diga agora aonde devo ir? Me diga agora mano? Me diga agora!”

${ }_{45}$ "Mais do que nunca a Fortaleza é DEF" - Ataque Frontal (ZMC e Ligado).

${ }^{46}$ PESAVENTO, Sandra, cit., p.15. 
${ }^{47}$ É interessante a reflexão feita por STAM, Robert. Bakhtin: da teoria literária à cultura de massa. São Paulo: Ática, 1992. p.75-6: "Porém os mesmos mecanismos dialógicos básicos operam também dentro da chamada 'cultura popular'. Veja-se, por exemplo, o fenômeno do hip-hop nos Estados Unidos, que inter-relaciona os universos culturais do rap, do grafite e da dança break. O rap, forma de música popular que utiliza os efeitos pirotécnicos executados em toca-discos combinados com um discurso verbal agressivo e ritmado - a própria palavra rap significa conversar, dialogar — , pode ser considerado uma esperta visão 'de rua' das teorias bakhtinianas sobre o dialogismo. Criado por adolescentes negros e hispânicos da classe operária ou lúmpen, o rapé intensamente, exuberantemente dialógico". 48 "Tortura" — Estado Indigente.

${ }_{49}$ "Ceará e seus problemas" - Conscientes do Sistema. Este rap dá título ao primeiro disco inteiramente de rap do Ceará. O grupo era ligado ao $\mathrm{MH}_{2} \mathrm{O}$, de onde saiu para fazer carreira solo. Recentemente se desmembrou em dois, ficando uma parte ainda com o nome de Conscientes do Sistema, e o outro passando a chamar-se de Consciência Armada, nome de uma das composições desse CD.

${ }^{50}$ Ambas as manifestações se consideram "culturas de rua”.

${ }^{51}$ "O cotidiano que se apreende no rock é o da deambulação. Trata-se da negação de um cotidiano tradicional e da afirmação de um cotidiano de rua. O lugar do dia-a-dia deixa de ser a casa para ser a cidade. Uma cidade com suas ruas e esquinas, com pistas de carro em alta velocidade, dos gigantescos anúncios luminosos, da multiplicidade de informações, da multidão nas calçadas, da intensa movimentação nos bares, dos encontros furtivos e, sobretudo, do anonimato. Seus personagens não têm nomes...”. GUERREIRO, Almerinda Sales. Retratos de uma tribo urbana: rock brasileiro. Dissertação (Mestrado) Faculdade de Filosofia, Letras e Ciências Humanas, Depto. de Antropologia, USP. São Paulo, 1991. p.83.

52 "O Poder da Palavra" - Rap Força.

53 “Sangue Negro” — Conexão Racial.

54 "Filhos da Rua" - Flip Rap.

${ }^{55}$ Entrevista realizada por este pesquisador com Eliane 'Zueira' em 12 fev. 2003 na Praça José de Alencar, Fortaleza. p.2.

${ }^{56}$ Flor Punk, cit., p.3.

${ }^{57}$ Entrevista realizada por este pesquisador com o punk Lezado, em 20 fev. 2003, em sua residência no bairro do Conjunto Ceará, Fortaleza. p.1.

${ }^{58}$ CAIAFA, Janice. Movimento Punk na Cidade: a invasão dos bandos sub. Rio de Janeiro: Jorge Zahar, 1985. p.49.

${ }^{59}$ PERALVA, Angeline. O jovem como modelo cultural. Juventude/Contemporaneidade, Revista Brasileira de Educação, São Paulo: Anped, n.5-6, 1997. p.23. 